\begin{tabular}{|c|l|}
\hline Title & Prediction Performance of Blackout and Plasma A ttenuation in A tmospheric Reentry Demonstrator Mission \\
\hline Author(s) & Takahashi, Y usuke; Y amada, Kazuhiko; A be, Takashi \\
\hline Citation & $\begin{array}{l}\text { Journal of Spacecraft and Rockets, 51(6), 1954 1964 } \\
\text { https://doi.org/10.2514/.A 32880 }\end{array}$ \\
\hline Issue Date & 201411 \\
\hline Doc URL & http://hdl.handle.net/2115/57530 \\
\hline Rights & ○ 2014 A merican Institute of A eronautics and A stronautics \\
\hline Type & article (author version) \\
\hline File Information & paperforjournal-ard.pdf \\
\hline
\end{tabular}

Instructions for use 


\title{
Prediction Performance of Blackout and Plasma Attenuation in Atmospheric Reentry Demonstrator Mission
}

\author{
Yusuke Takahashi ${ }^{1}$ \\ Hokkaido University, Kita 13 Nishi 8, Kita-ku, Sapporo, Hokkaido, 060-8628, Japan, \\ Kazuhiko Yamada ${ }^{2}$ and Takashi $\mathrm{Abe}^{3}$, \\ Japan Aerospace Exploration Agency, 3-1-1 Yoshinodai Chuo-ku, Sagamihara, Kanagawa \\ 252-5210, Japan
}

\begin{abstract}
A numerical simulation model that combines the plasma flows and electromagnetic waves around a reentry vehicle during atmospheric reentry was developed to evaluate the radio frequency blackout and plasma attenuation. The physical properties of the plasma flow in the shock layer and wake region were obtained using a computational fluid dynamics technique. The electromagnetic waves were expressed using a frequencydependent finite-difference time-domain method with the plasma properties. Combined simulations were performed for the atmospheric reentry demonstrator of the European Space Agency at various altitudes based on reentry orbit data. The electromagnetic wave behaviors around the vehicle during atmospheric reentry were investigated in detail. Moreover, a parametric analysis with different ionization reaction models was performed. It was confirmed that the vehicle is surrounded by the plasma and the propagation of the electromagnetic waves is prevented at high altitude. Then, the plasma is dissipated, and the propagation recovers at low altitude. Validation of the simulation model was performed based on the plasma attenuation history of the experimental flight data. A comparison of the measured and predicted results showed good agreement. It was concluded that the combined simulation model could be an effective tool for investigating the radio frequency blackout and the plasma attenuation of radio wave communication.
\end{abstract}

\section{Nomenclature}

$\begin{array}{lll}\mathbf{B} & =\text { magnetic flux density vector, } \mathrm{T} \\ C & =\text { mass faction } \\ D & =\text { effective diffusion coefficient, } \mathrm{m}^{2} / \mathrm{s} \\ \mathcal{D} & = & \text { binary diffusion coefficient, } \mathrm{m}^{2} / \mathrm{s} \\ \mathbf{D} & = & \text { electric flux density vector, } \mathrm{C} / \mathrm{m}^{2} \\ e & = & \text { electric charge, } \mathrm{C} \\ \mathbf{E} & = & \text { electric field vector, } \mathrm{V} / \mathrm{m} \\ f & = & \text { frequency, } \mathrm{Hz} \\ \mathbf{J} & = & \text { current density vector, } \mathrm{A} / \mathrm{m}^{2} \\ \mathbf{H} & = & \text { magnetic field vector, } \mathrm{A} / \mathrm{m} \\ m & = & \text { mass, } \mathrm{kg} \\ n & = & \text { number density, } 1 / \mathrm{m}^{3} \\ t & = & \text { time, } \mathrm{s}\end{array}$

\footnotetext{
${ }^{1}$ Assistant Professor, Faculty of Engineering; ytakahashi@eng.hokudai.ac.jp.

${ }^{2}$ Assistant Professor, Institute of Space and Astronautical Science.

${ }^{3}$ Professor, Institute of Space and Astronautical Science.
} 


$\begin{array}{lll}T= & \text { temperature, } \mathrm{K} \\ V & =\text { diffusion velocity, } \mathrm{m} / \mathrm{s} \\ X & =\text { Mole fraction } \\ \delta & = & \text { Kronecker delta } \\ \varepsilon_{\mathrm{r}} & = & \text { relative permittivity } \\ \varepsilon_{0} & = & \text { permittivity in free space, } \mathrm{N} / \mathrm{V}^{2} \\ \mu_{0} & = & \text { permeability in free space, } \mathrm{N} / \mathrm{A}^{2} \\ \nu_{\mathrm{c}} & = & \text { collision frequency, } \mathrm{Hz} \\ \rho & = & \text { density, } \mathrm{kg} / \mathrm{m}^{3} \\ \sigma & = & \text { conductivity, } \mathrm{S} / \mathrm{m} \\ \chi & = & \text { electric susceptibility } \\ \omega_{\mathrm{p}} & = & \text { plasma angular frequency, } \mathrm{rad} / \mathrm{sec}\end{array}$

$\begin{array}{lll}\text { Subscripts } & \\ \mathrm{e}= & \text { electron } \\ \mathrm{ex}= & \text { electronic excitation } \\ \mathrm{p}= & \text { plasma } \\ \mathrm{rot}= & \text { rotation } \\ \mathrm{s}= & \text { species } \\ \mathrm{tr} & = & \text { translation } \\ v & = & \text { viscous } \\ \mathrm{vib}= & \text { vibration }\end{array}$

\section{Introduction}

One of the most important issues in the entry, descent, and landing (EDL) approach is radio frequency $(\mathrm{RF})$ blackout and plasma attenuation, that is, the cutoff of communications between the reentry vehicle and the ground stations and/or data-relay satellites. During atmospheric reentry from a low Earth orbit, the vehicle flies at more than $7 \mathrm{~km} / \mathrm{s}$, and a strong shock wave is formed at its front. Air is dissociated and ionized by strong aerodynamic heating in the shock-wave layer. A large number of electrons and ions are generated, and these charged particles cover the vehicle surface. RF blackout is caused by the plasma layer on the vehicle surface attenuating or reflecting the electromagnetic waves used for telecommunication, navigation, guidance, and control. In fact, thus far, this RF blackout has been observed in many reentry flight tests, including those of the RAM-C II, Apollo command module (NASA), and OREX (NASDA/NAL, currently JAXA).

In recent years, JAXA has initiated the Membrane Aeroshell for Atmospheric-entry Capsule (MAAC) project, which has the goal of developing an inflatable reentry vehicle. Because these missions also focus on a demonstration of recovery, RF blackout is a significant concern from the viewpoint of the precise determination of the vehicle's position and control, and it is desirable to avoid RF blackout during reentry. In general, the thick plasma in front of the reentry vehicle generated by a shock wave strongly prevents electromagnetic waves from propagating in the traveling direction of the vehicle. On the other hand, a relatively easy propagation of electromagnetic waves is expected in the rear of the vehicle, because the plasma flow is rapidly cooled and rarefied by expansion when the compressed gas in the shock layer flows toward the rear of the vehicle, and electron number density decreases. In fact, it 
was suggested in Ref. $[1,2]$ that an inflatable vehicle passively reduces the RF blackout with a data-relay satellite during atmospheric reentry on account of its low-ballistic coefficient flight and distinctive vehicle configuration. Moreover, an RF blackout mitigation method that uses a magnetic field has been investigated [3]. Thus, it may be possible for a vehicle with such features to communicate without RF blackout during a mission. The ballistic coefficient and vehicle configuration can also be used as design parameters for RF blackout and plasma attenuation. To estimate the possibility of RF blackout and plasma attenuation during the vehicle design process, it is important to investigate the reflection and attenuation of electromagnetic waves around the vehicle in detail.

Because the RF blackout phenomenon is affected by the flow properties around the vehicle, specifically the number density of electrons, we need to clarify the distribution of charged particles. However, it is difficult to completely reproduce the environment in which RF blackout is caused by using ground testing facilities such as a hypersonic wind tunnel, archeated wind tunnel, and ballistic range. In recent times, remarkable progress has been made in the development of high-performance computers and algorithms for numerical simulation. Numerical prediction has become a powerful tool for investigating the details of phenomena such as a flow field or an electromagnetic wave and for the design and development of reentry vehicles.

Now, the computational fluid dynamics (CFD) method is an effective diagnosis technique for determining the plasma flow behavior around a reentry vehicle. On the other hand, the frequency-dependent finite-difference time-domain (FD2TD) method [4] is also an effective tool for simulating electromagnetic waves in a frequency-dependent medium (e.g., plasma) whose dielectric constant and electrical conductivity vary over a frequency range. In fact, Kinefuchi et al. [5] reported that the FD2TD computational results for the microwave propagation around a rocket plume showed good agreement with experimental results. Cummer [6] proposed two effective FDTD methods for isotropic cold plasma. In addition to the above applications of electromagnetic wave simulation, recently, a prediction technique for the RF blackout and plasma attenuation of a reentry vehicle, based on a combination of CFD and FD2TD, was suggested by Takahashi et al. [1,2]. However, there are some uncertainties when using physical and numerical models for plasma properties (e.g., transport coefficients, chemical reaction models, internal energy exchange model, etc.) in a high-temperature region. It is unclear how these uncertainties in the plasma models influence the propagation of electromagnetic waves near a reentry vehicle. Moreover, an unexpected physical phenomenon may greatly affect the prediction. Thus, it is necessary to validate the combination model for the plasma flow and electromagnetic waves.

In 1998, the atmospheric reentry demonstrator (ARD) [7] of the European Space Agency (ESA) was launched by the Ariane 5 rocket and reentered the Earth's atmosphere. Throughout its reentry, detailed plasma attenuation profiles of the radio waves between the ARD and a global positioning system (GPS) satellite and the tracking and data relay satellite (TDRS) were measured. We focus on the validation of the present electromagnetic wave simulation, that is, the prediction performance for the RF blackout and plasma attenuation of future reentry vehicle designs. For this purpose, the plasma attenuation history and flight trajectory of the ARD mission are effective data. In the present study, the plasma and electromagnetic wave behaviors around the ARD are numerically investigated. Moreover, the simulation model is validated using the results measured in the ARD mission. 


\section{ARD Flight}

Before validating the present simulation model, a brief overview of the ARD mission is presented in this section. The ARD had the same configuration as an Apollo command module scaled down to $70 \%$ as shown in Fig. 1. It comprised three key components: the front shield section, rear cone section, and back cover section. The capsule was essentially a spherical cone with a nose radius of $3360 \mathrm{~mm}$ and a base radius of $2800 \mathrm{~mm}$ for the front shield section and a half-angle of $33^{\circ}$ for the rear section. At the rear cone, the top part was cut down, and a step part was created.

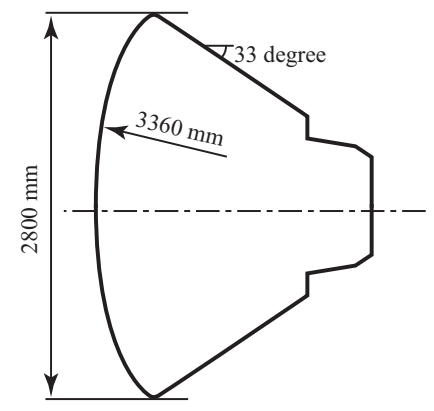

Figure 1: External configuration of ARD.

The ARD capsule was launched by the Ariane-5 V503 rocket on October 21, 1998, and was separated from the Ariane- 5 at an altitude of $218 \mathrm{~km}$. The ARD reached its apogee at an altitude $830 \mathrm{~km}$, and then reentered the Earth's atmosphere. It was reported that the reentry velocity at an altitude of $120 \mathrm{~km}$ was approximately $7452 \mathrm{~m} / \mathrm{s}$. Because of its high reentry velocity, it is thought that a shock wave was generated in front of the vehicle, and the vehicle was surrounded by plasma. Heat flux on the front surface was inferred to reach a peak value of approximately $1.2 \mathrm{MW} / \mathrm{m}^{2}$ at an altitude of $65 \mathrm{~km}$ and a Mach number of 23.5. After deceleration by the aerodynamic force, the ARD began its recovery sequence. First, a pilot chute was deployed during the period in which the vehicle descended from $17.3 \mathrm{~km}$ to $7.3 \mathrm{~km}$. Then, a drogue chute was pulled out by the pilot chute to stabilize the vehicle. The three main chutes were deployed between $8 \mathrm{~km}$ and $1.7 \mathrm{~km}$ altitudes. Finally, the ARD splashed down in the Pacific Ocean at a terminal velocity of $6.7 \mathrm{~m} / \mathrm{s}$. The reentry trajectory (position, velocity, and attitude reconstructed by acceleration measurements) was obtained using on-board inertial navigation system measurements and a GPS receiver.

The ARD employed eight dedicated skin antennas for a telemetry link and communication with the GPS satellites, TDRS, and airplanes (ARIA 1 and ARIA 2) during its flight. The GPS and TDRS link frequencies were approximately 1.575 and $2.267 \mathrm{GHz}$, respectively. Measurements were made of the RF blackout and plasma attenuation caused by the plasma around the vehicle generated by the shock wave. The beginning and end of the RF blackout for the GPS link on the trailing edge were at altitudes of $90 \mathrm{~km}$ and $40 \mathrm{~km}$, respectively. On the other hand, no RF blackout for the TDRS link was observed, even though a strong plasma attenuation of the link was measured from an altitude of $86 \mathrm{~km}$ to an altitude of 44 $\mathrm{km}$.

The flight path angle of the ARD, along with its altitude, can be deduced from the ARD flight trajectory [7]. Then, the direction of the TDRS position to the ARD flight path can be identified using the TDRS position information. According to Tran's report [7], it is thought that the TDRS was located west of Greenwich at $-171^{\circ}$ on the geostationary earth orbit on 
the date of the ARD mission. Figure 2 shows the angle history of the TDRS direction to the ARD flight path. It clarifies that the angle ranges from $90^{\circ}$ to $100^{\circ}$ at altitudes between $90 \mathrm{~km}$ and $40 \mathrm{~km}$, where the BF blackout and plasma attenuation appear. Moreover, the TDRS direction to the ARD axis can be estimated using the history of the angle of attack (about $-20^{\circ}$ ). Thus, it is deduced that the TDRS was located at an angle between $110^{\circ}$ and $120^{\circ}$ relative to the $\mathrm{ARD}$ axis at the altitude.

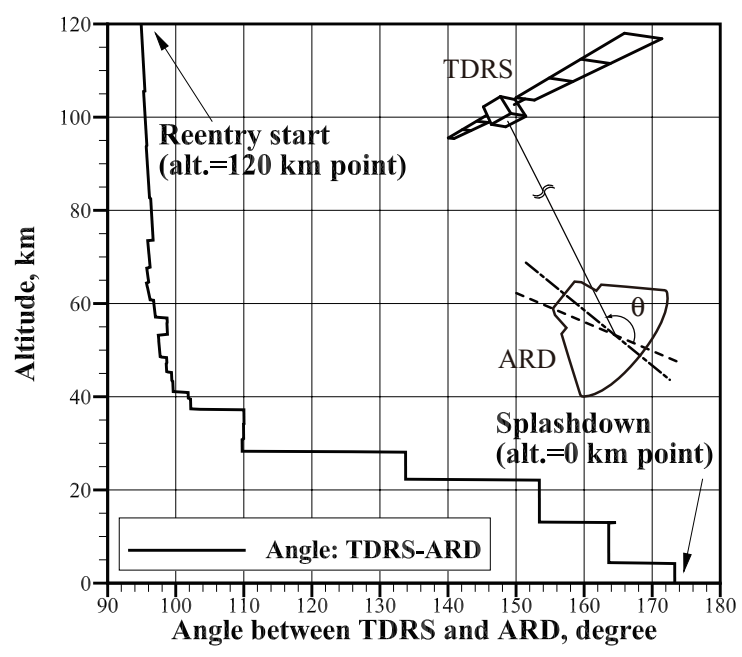

Figure 2: Angle of TDRS position to ARD flight path.

\section{Formulations}

The physical models used here are essentially the same as those in our previous studies on plasma flow and electromagnetic wave simulations (see also Ref. [8]) except for the calculation conditions. However, a more detailed diffusion flux model is introduced in the plasma flow simulation. In this section, the present governing equations, physical models, and numerical method are briefly described.

\subsection{Flow Field}

\subsubsection{Governing equations}

In this study, the following assumptions are made. (1) The flow is laminar, steady, continuum, and axisymmetric. (2) The inflow gas is air. (3) The flow field is in thermochemical nonequilibrium, and the temperature is separated into translational $\left(T_{\mathrm{tr}}\right)$, rotational $\left(T_{\mathrm{rot}}\right)$, vibrational $\left(T_{\mathrm{vib}}\right)$, and electron $\left(T_{\mathrm{e}}\right)$ temperatures. Note that the electronic-excitation energy mode and the electron energy are assumed to be equilibrated (that is, electronic-excitation temperature: $T_{\mathrm{ex}}=T_{\mathrm{e}}$ ).

The flow field is described by the Navier-Stokes equations with a multi-temperature model and the equation of state. The NS equations include the total mass, momentum, total energy, species mass, rotation energy, vibration energy, and electron energy conservations. 
Transport properties such as the viscosity, thermal conductivity, and binary diffusion coefficients for a mixture gas are evaluated using Yos' formula, which is based on the first Chapman-Enskog expansion. The collision cross sections are taken from the study of Gupta et al. [9]. However, for e-N and e-O pairs, the model by Fertig et al. [10,11] is used. The diffusion flux is calculated using Jones and Boris's formula [12], which is expressed as follows:

$$
\rho_{s} V_{s}^{j}=-\rho D_{s}\left[\left(\delta_{s k}+A_{s k}+A_{s l} A_{l k}+\cdots\right) d_{k}^{j}\right]
$$

and the effective diffusion coefficient $D_{s}$, matrix $A_{s k}$, and vector $d_{k}^{j}$ are respectively obtained by the follows expressions:

$$
D_{s}=\frac{1-C_{s}}{\sum_{k \neq s}^{n s} X_{k} / \mathcal{D}_{s k}} \frac{C_{s}}{X_{s}}, \quad A_{s k}=C_{s} \delta_{s k}+\frac{X_{s}}{\mathcal{D}_{s k}} \frac{1-C_{k}}{\sum_{l \neq k}^{n s} X_{l} / \mathcal{D}_{k l}}\left(1-\delta_{s k}\right), \quad d_{k}^{j}=\frac{\partial X_{k}}{\partial x^{j}} .
$$

Here, $\mathcal{D}_{s k}$ is the binary diffusion coefficient between the species " $s$ " and " $k$," and $d_{k}$ indicates the spatial gradient of the mole fraction. Note that the diffusion flux model corresponds to the formula of Curtiss and Hirschfelder [13] when considering only the zeroth order (i.e., neglecting the matrix $A_{s k}$ ) of Eq. (1). Ambipolar diffusion is assumed for charged species such as $D_{s}^{a}=\left(1+T_{\mathrm{e}} / T_{\mathrm{tr}}\right) D_{s}$.

For chemical reactions in high-temperature air, the test gas is assumed to consist of 11 chemical species $\left(\mathrm{N}_{2}, \mathrm{O}_{2}, \mathrm{NO}, \mathrm{N}_{2}^{+}, \mathrm{O}_{2}^{+}, \mathrm{NO}^{+}, \mathrm{N}, \mathrm{O}, \mathrm{N}^{+}, \mathrm{O}^{+}\right.$, and $\left.\mathrm{e}^{-}\right)$, and 49 reactions are assumed to occur. In the present study, the forward and backward reaction rates of the chemical reaction are given by Park's model [14]. The forward reaction rate is determined using an Arrhenius-type form as

$$
k_{\mathrm{f}, r}\left(T_{\mathrm{f}, r}\right)=C_{r} T_{\mathrm{f}, r}^{s_{r}} \exp \left(-\theta_{r} / T_{\mathrm{f}, r}\right),
$$

where $C_{r}, s_{r}$, and $\theta_{r}$ are the reaction rate coefficients. On the other hand, the backward reaction rate is evaluated from the equilibrium constants $K_{r}^{\mathrm{eq}}$ :

$$
k_{\mathrm{b}, r}\left(T_{\mathrm{b}, r}\right)=k_{\mathrm{f}, r}\left(T_{\mathrm{b}, r}\right) / K_{r}^{\mathrm{eq}}\left(T_{\mathrm{b}, r}\right),
$$

where $T_{\mathrm{f}}$ and $T_{\mathrm{b}}$ are the effective temperatures for the forward and backward reactions, respectively. The equilibrium constants, being functions of only the temperature, are calculated by the curve-fit formula given in Ref. [15].

We consider the energy transfer between each pair of internal energy modes: translationrotation (T-R) [16], translation-vibration (T-V) [17, 18], translation-electron (T-e) [19-21], rotation-vibration (R-V) [16], rotation-electron (R-e) [22, 23], and vibration-electron (V-e) [24]. The energy losses/releases for vibrations, $Q_{\mathrm{D}}^{\mathrm{vib}}$, and rotations, $Q_{\mathrm{D}}^{\text {rot }}$, associated with chemical reactions reveal the dissociation energies for heavy-particle-impact reactions. These can be obtained using a non-preferential dissociation model [25]. In addition, the electron energy losses/releases due to electron-impact dissociation, $Q_{\mathrm{D}}^{\mathrm{e}}$, and ionization, $Q_{\mathrm{I}}^{\mathrm{e}}$, are also considered.

\subsubsection{Numerical method}

The governing equations are transformed to the generalized coordinate system and solved using a finite volume approach. All the flow properties are set at the center of a control volume. The inviscid fluxes in the flow-field equations are evaluated using the SLAU scheme [26], and 
Table 1: Computational conditions

\begin{tabular}{c|ccccccc}
\hline \hline Altitude, $\mathrm{km}$ & 92 & 90 & 87 & 85 & 83 & 80 & 77 \\
\hline Density, kg/m & $2.42 \mathrm{E}-6$ & $3.46 \mathrm{E}-6$ & $5.85 \mathrm{E}-6$ & $8.22 \mathrm{E}-6$ & $1.15 \mathrm{E}-5$ & $1.85 \mathrm{E}-5$ & $3.00 \mathrm{E}-5$ \\
Temperature, K & 184.9 & 188.3 & 189.9 & 191.0 & 192.8 & 195.8 & 199.2 \\
Velocity, m/s & 7540 & 7545 & 7566 & 7577 & 7588 & 7609 & 7600 \\
\hline \hline
\end{tabular}

\begin{tabular}{cccccccc}
\hline \hline 75 & 73 & 70 & 65 & 60 & 50 & 45 & 40 \\
\hline $4.01 \mathrm{E}-5$ & $5.62 \mathrm{E}-5$ & $8.83 \mathrm{E}-5$ & $1.78 \mathrm{E}-4$ & $3.40 \mathrm{E}-4$ & $1.15 \mathrm{E}-3$ & $2.25 \mathrm{E}-3$ & $4.36 \mathrm{E}-3$ \\
201.7 & 205.1 & 210.9 & 225.3 & 242.0 & 265.2 & 255.6 & 250.3 \\
7592 & 7546 & 7452 & 7145 & 6105 & 4567 & 3323 & 2218 \\
\hline \hline
\end{tabular}

all the viscous terms are calculated using the second-order central difference method. The spatial accuracy is thus essentially of the second order. Time integration is performed using an implicit time-marching method. The governing equation system is transformed into the delta form, and the solution is updated at each time step. When modeling the thermochemical nonequilibrium flow, we need to introduce a robust and effective time-integration scheme to overcome the stiffness caused by the large time-scale difference between the chemical reactions and the fluid motion, which results in a severe restriction of the Courant-Friedrich-Lewy condition. Therefore, we employ the lower-upper symmetric Gauss-Seidel (LU-SGS) method coupled with the point-implicit method [27].

\subsubsection{Boundary conditions}

As the boundary conditions, at the inflow, the freestream parameters are given, following the orbit data. At the outflow, all the flow properties are determined by the zeroth extrapolation because the flow is supersonic in most regions. The non-slip condition for the velocity and the non-catalytic condition for the mass concentration are imposed at the wall surfaces. No pressure gradient is assumed to be normal to the wall. The translational $\left(T_{\mathrm{tr}}\right)$, rotational $\left(T_{\text {rot }}\right)$, and vibrational $\left(T_{\text {vib }}\right)$ temperatures are fixed at the wall and are set to be $800 \mathrm{~K}$. The electron temperature $\left(T_{\mathrm{e}}\right)$ is assumed to be adiabatic at the wall. An axisymmetric condition is imposed along the symmetry axis.

\subsubsection{Calculation conditions}

The present calculations are performed for 15 cases with altitudes between $92 \mathrm{~km}$ and $40 \mathrm{~km}$. Inflow parameters such as the freestream velocity, density, and temperature are set according to the flight conditions in Ref. [7] as listed in Table 1. The degree of ionization at the inflow is always set to a small value $10^{-10}$ for stable computation. At altitudes of $92-40 \mathrm{~km}$, the Knudsen number considered here is smaller than 0.01. Thus, the continuum flow assumption is expected to be justified. The computational grid system for a typical case is shown in Fig. 3, although different grid systems are used at each altitude. Note that the calculation geometry is simplified. 


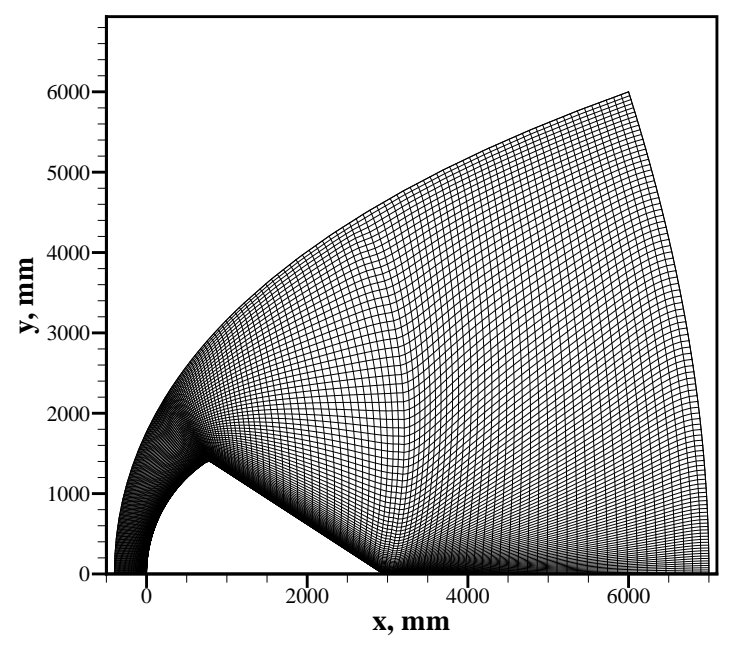

Figure 3: Computational grids system for CFD at altitude of $85 \mathrm{~km}$.

\subsection{Electromagnetic Wave}

Maxwell's equations for describing the behavior of electromagnetic waves in plasma are numerically discretized using the FD2TD method. In the present FD2TD formulation, the complex relative permittivity $\left(\varepsilon_{\mathrm{r}}^{*}\right)$, assuming the first Drude dispersion, is given by

$$
\varepsilon_{\mathrm{r}}^{*}=1+\frac{\omega_{\mathrm{p}}^{2}}{\omega\left(i \nu_{c}-\omega\right)}=1+\chi(\omega)
$$

where $\omega_{\mathrm{p}}, \nu_{\mathrm{c}}$, and $\chi(\omega)$ respectively denote the plasma angular frequency, electron collision frequency, and electric susceptibility at a given angular frequency $(\omega)$. Note that $i$ represents an imaginary unit. The complex relative permittivity can be expressed with the relative permittivity $\left(\varepsilon_{\mathrm{r}}\right)$ and dielectric conductivity $(\sigma)$ as follows:

$$
\varepsilon_{\mathrm{r}}^{*}=\varepsilon_{\mathrm{r}}+\frac{\sigma}{i \omega \varepsilon_{0}}
$$

where

$$
\begin{gathered}
\varepsilon_{\mathrm{r}}=1-\frac{\omega_{\mathrm{p}}^{2}}{\omega^{2}+\nu_{\mathrm{c}}^{2}}, \\
\sigma=\frac{\varepsilon_{0} \omega_{\mathrm{p}}^{2}}{\omega^{2}+\nu_{\mathrm{c}}^{2}} \nu_{\mathrm{c}} .
\end{gathered}
$$

The computational domain for electromagnetic waves is set to be a cuboid with a $7.0 \mathrm{~m}$ length in the $x$ direction, $6.0 \mathrm{~m}$ width in the $y$ direction, and $6.0 \mathrm{~m}$ height in the $z$ direction. The computational grid nodes are set to 500 in the $x$ direction, 300 in the $y$ direction, and 300 in the $z$ direction (i.e., 45 million nodes). As shown in Fig. 4, the ARD is included in the cuboid, and the origin of the CFD computational domain corresponds to that of the electromagnetic-wave calculation domain. The physical properties $\left(\omega_{\mathrm{p}}, \nu_{\mathrm{c}}\right)$ required in the present FD2TD are provided by referring to the computational results obtained by CFD. Note that the flow-field computations are performed under the two-dimensional axisymmetric 


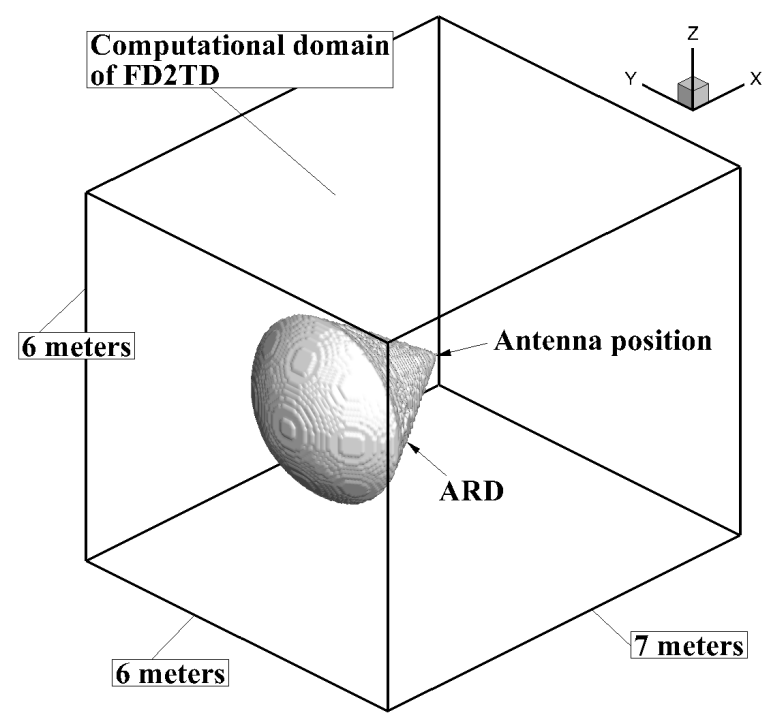

Figure 4: Computational domain of FD2TD method.

assumption, and the flow properties are assumed to be uniform in the circumstance direction. A node on the FD2TD grid system is normally surrounded by eight grid points in the CFD domain. The plasma properties at a node positioned in the CFD cell are interpolated using the computed data for each point. On the other hand, the plasma parameters at a node of FD2TD positioned outside the CFD domain are given by the parameters at the nearest boundary point of the CFD domain. The magnetic permeability $(\mu)$ is assumed to be the same as the free space $\left(\mu_{0}\right)$ for simplicity. Mur's absorption boundary condition [28] is imposed as a boundary condition at all six faces of the computational domain.

\section{Results and Discussion}

To evaluate the RF blackout and plasma attenuation during atmospheric reentry, it is important to predict the distribution of the number density of the electrons and the electromagnetic waves around the vehicle. In this section, we first clarify the distributions of the plasma properties, such the electron number densities at various flight altitudes, using the CFD technique. Then, we evaluate the propagation of electromagnetic waves using the FD2TD method. Finally, we investigate the plasma attenuation and RF blackout using the CFD and FD2TD results.

\subsection{Plasma Properties}

Figures 5(a) and 5(b) respectively show the axial profiles of the temperatures and mole fractions along the center axis of the ARD at an altitude of $85 \mathrm{~km}$. As can be seen, each of the temperatures is thoroughly separated, and strong thermal nonequilibrium appears in the flow field. This is because the air density at this altitude is low, and the energy exchanges between the internal energy modes become slow. At the same time, toward the surface from the free stream, the temperatures are seen to be equilibrated as a result of an increase in the number of collisions with an increase in density. The electron temperature increases upstream of the shock wave. This is because the thermal conductivity of electrons becomes relatively 


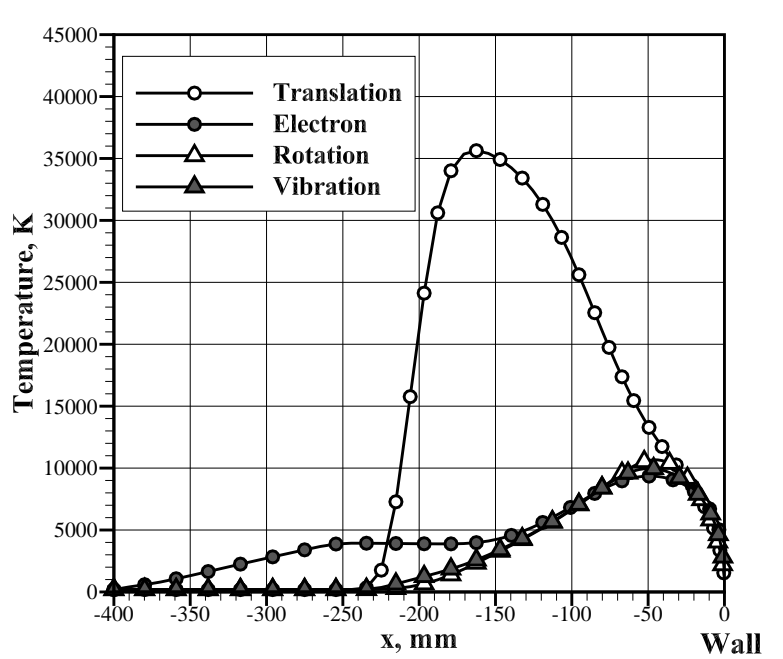

(a) Axial profile of temperatures

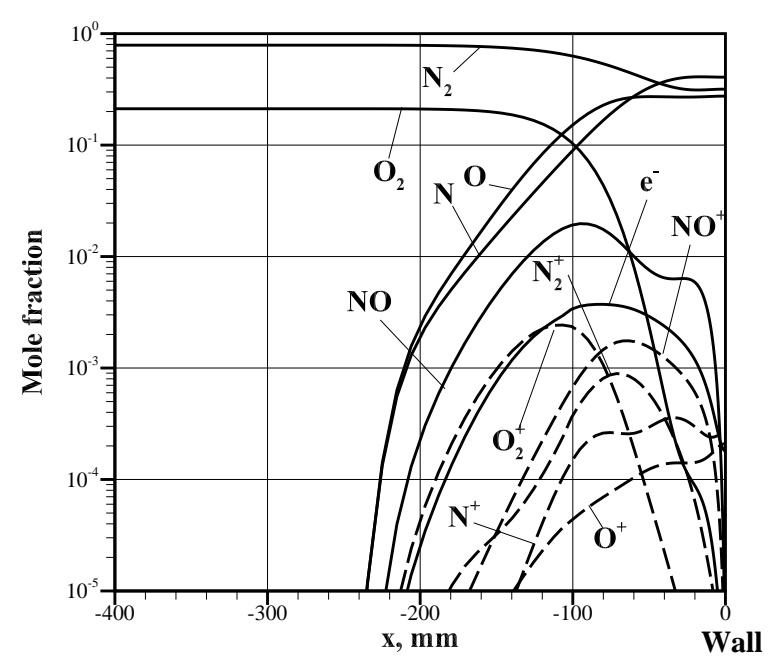

(b) Axial profile of mole fractions

Figure 5: Axial profiles of temperatures and mole fractions along center axis in front of ARD's flow field at altitude of $85 \mathrm{~km}$.

high in the region of low electron density and heat conduction from the shock layer highly occurs.

As in the case of the temperature behavior mentioned above, chemical reactions appear to occur at a slow rate. The dominant reactions are dissociations of molecules, and the gas species in the shock layer include mainly molecular nitrogen, atomic nitrogen, and atomic oxygen. Moreover, a small number of electrons are also generated. In the wake region, fewer dissociation and ionization reactions occur with a decrease in temperature. Thus, the behavior of charged particles in the vehicle's wake is determined mainly by the chemical reactions occurring in front of the vehicle. However, the chemical reaction models used here were developed based on shock tube experiments. In an expansion flow region such as the vehicle wake, a large uncertainty can exist. In particular, the associative ionization reactions are an important ionization mechanism at the altitudes considered here, and it is known that these reaction models may contain large errors.

When the plasma above an antenna is assumed to be sufficiently thick, electromagnetic waves with a frequency smaller than a given value are reflected by the plasma layer. The critical plasma frequency is generally given as a function of the electron number density. The cut-off frequency preventing electromagnetic waves from reaching the antenna can be evaluated by using the critical number density of the electrons. The link frequency between the vehicle and the data-relay satellite is set to be $2.267 \mathrm{GHz}$, and thus, the number density $\left(n_{\mathrm{e}, \mathrm{crit}}\right)$ is found to be $6.4 \times 10^{16} 1 / \mathrm{m}^{3}$.

The distributions of the number density of the electrons around the ARD at altitudes of 85, 80, 75, 70, 60, and $50 \mathrm{~km}$ are illustrated in Figs. 6(a)-6(f). A region appears to exist in which the number density of the electrons generated by the shock layer remains high at each altitude. When the electromagnetic waves pass through the regions where the electron density exceeds the critical value for the link frequency, attenuation, refraction, or reflection will occur. On the other hand, at the rear of the vehicle, the number density of the electrons decreases to well below the critical value, except at the altitudes between 80 and $60 \mathrm{~km}$. It is not expected that electromagnetic waves will be reflected in such a region; 
however, attenuation can occur if the medium in which the electromagnetic waves propagate is sufficiently conductive. At altitudes from $80 \mathrm{~km}$ to $60 \mathrm{~km}$, the electron number density increases at the rear. This is because the flow separated on the shoulder is converged, and the density of the gas increases slightly, whereas fewer ionization reactions occur at the rear. At an altitude of $75 \mathrm{~km}$, the ARD is almost completely surrounded by thick plasma, which exceeds the critical number density of electrons. This is indicated by the occurrence of the $\mathrm{RF}$ blackout at this altitude in the present simulation.

In the calculation of the diffusion flux, we consider the first order of Eq. (1). When only the zeroth order is considered (i.e., the diffusion model corresponds to the well-known Curtiss model [13]), it is confirmed that a lower distribution tends to be predicted for the electrons. On the other hand, the distribution of the electrons obtained by considering the first-order approximation hardly changes compared with that by considering the secondorder approximation. Thus, for the diffusion flux calculation, we conclude that the first-order approximation is sufficiently convergent.

\subsection{Electromagnetic Wave Propagation}

Figures $7(\mathrm{a})$ and $7(\mathrm{~b})$ show the distributions of the permittivity and dielectric conductivity in the $x-y$ plane $(z=0 \mathrm{~mm})$ of the FD2TD computational domain around the ARD at an altitude of $85 \mathrm{~km}$. Plasma properties such as the permittivity $(\varepsilon)$, plasma angular frequency $\left(\omega_{\mathrm{p}}\right)$, and collision frequency $\left(\nu_{\mathrm{c}}\right)$ are obtained from the abovementioned computational results. In the ionized gas, the permittivity is frequency-dependent and generally becomes low depending on the angular frequencies of the plasma $\left(\omega_{\mathrm{p}}\right)$ and the electromagnetic waves $(\omega)$ :

$$
\varepsilon(\omega)=\varepsilon_{0} \varepsilon_{\mathrm{r}}=\varepsilon_{0}\left(1-\frac{\omega_{\mathrm{p}}^{2}}{\omega^{2}+\nu_{\mathrm{c}}^{2}}\right) .
$$

Electromagnetic waves cannot propagate into a medium where $\omega_{\mathrm{p}}^{2}>\omega^{2}+\nu_{\mathrm{c}}^{2}$ and are perfectly reflected on its surface, because the permittivity is negative, and the index of refraction becomes an imaginary number. In addition, as the dielectric conductivity increases, the electromagnetic waves are strongly attenuated. Because the number density becomes high and the plasma angular frequency $\left(\omega_{\mathrm{p}}\right)$ is larger than the link angular frequency $(\omega)$ in the shock layer in front of the vehicle, the permittivity is negative. In the rear region of the ARD, because the dielectric conductivity is sufficiently high, while the permittivity recovers to a positive value, the plasma attenuation of the electromagnetic wave can be observed. Thus, it is difficult to accurately determine the electromagnetic wave behavior using only the information about the plasma flow field.

The electromagnetic wave simulations are performed using the FD2DT method for each altitude. These are very complicated to be analyzed considering the detailed antenna configuration and antenna feeding methods. Thus, the generation of electromagnetic waves is simply modeled for gaining a fundamental understanding in the present calculations. Transverse magnetic waves are generated as a wave source by inputting a sinusoidally electric field in the $z$ direction at the aft of the vehicle. The amplitude of the electric field at the source is set to unity $\left(E_{z 0}=1.0 \mathrm{~V} / \mathrm{m}\right)$. As previously mentioned, the frequency is $2.267 \mathrm{GHz}$, which corresponds to the TDRS link frequency.

Figures 8(a)-8(f) shows the electric field distributions of the electromagnetic waves around the ARD at altitudes of $85,80,75,70,60$, and $50 \mathrm{~km}$. The electromagnetic waves generated at the rear of the ARD are observed to propagate in the vehicle wake region and concentrically expand. In the present flow-field simulation, ionized gas in the shock layer in front of the ARD 


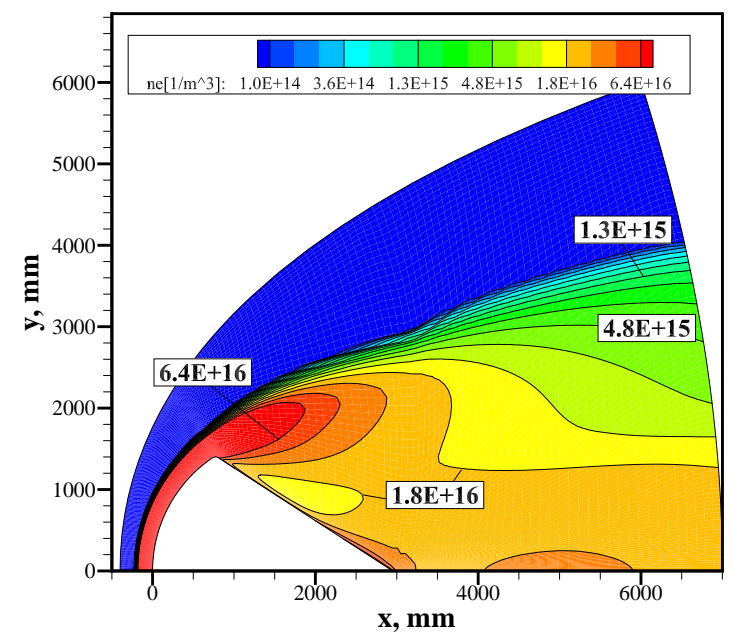

(a) altitude $85 \mathrm{~km}$

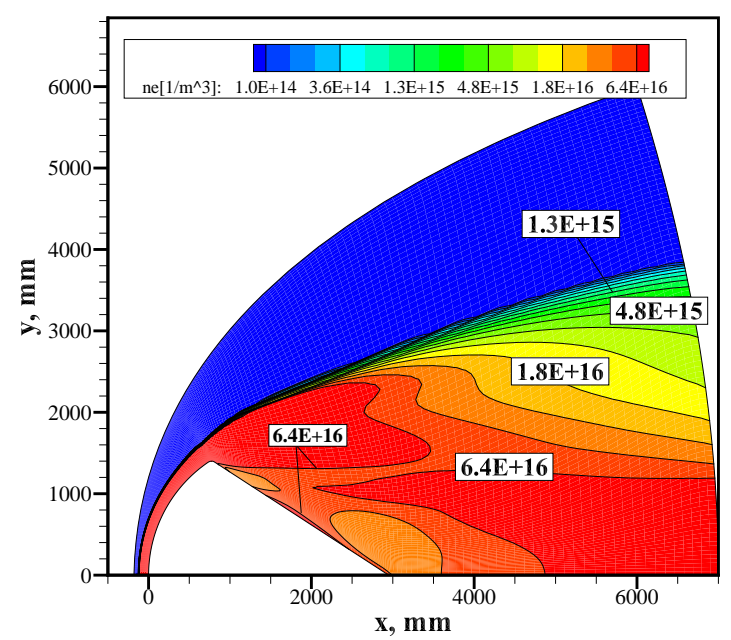

(c) altitude $75 \mathrm{~km}$

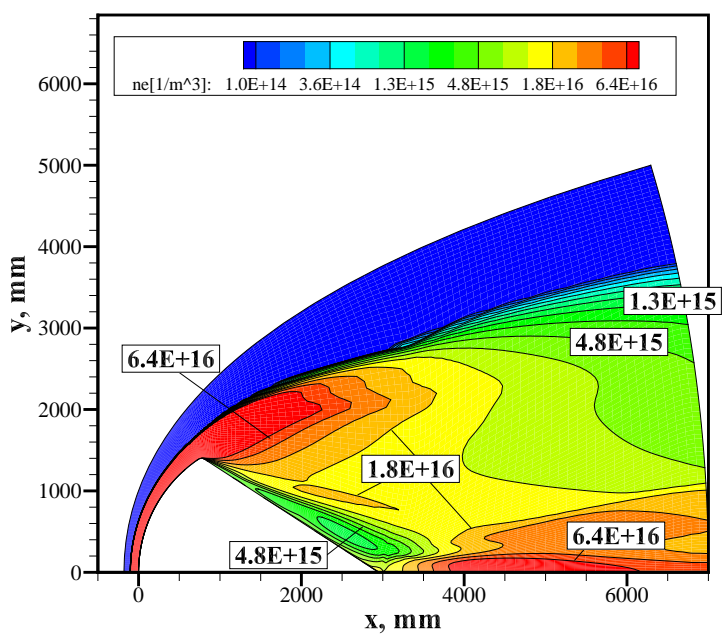

(e) altitude $60 \mathrm{~km}$

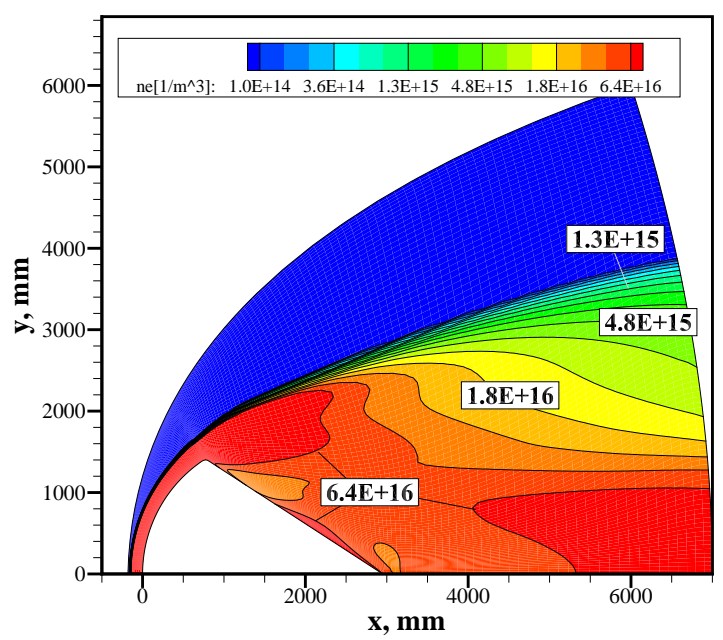

(b) altitude $80 \mathrm{~km}$

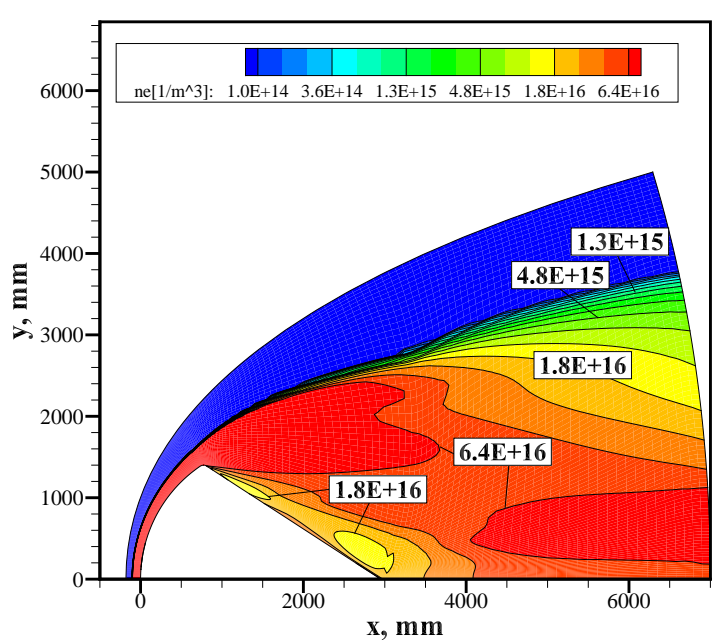

(d) altitude $70 \mathrm{~km}$

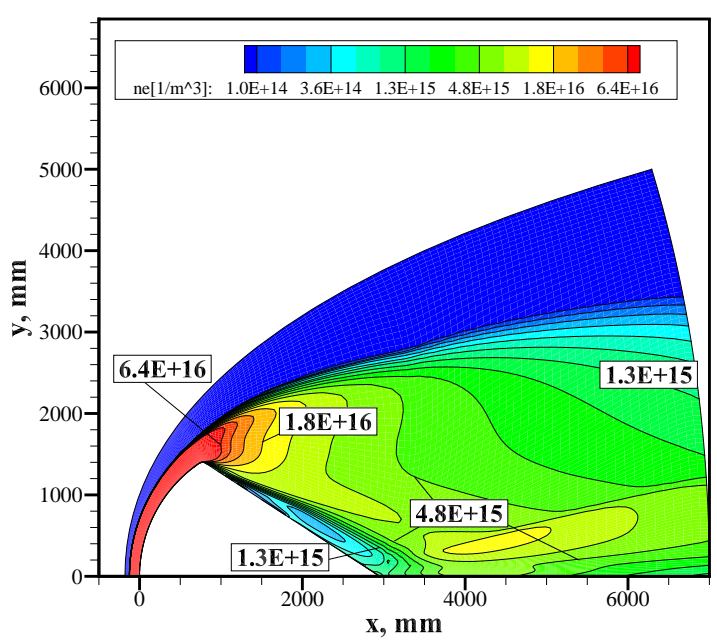

(f) altitude $50 \mathrm{~km}$

Figure 6: Distributions of number density of electrons around ARD at each altitude. 


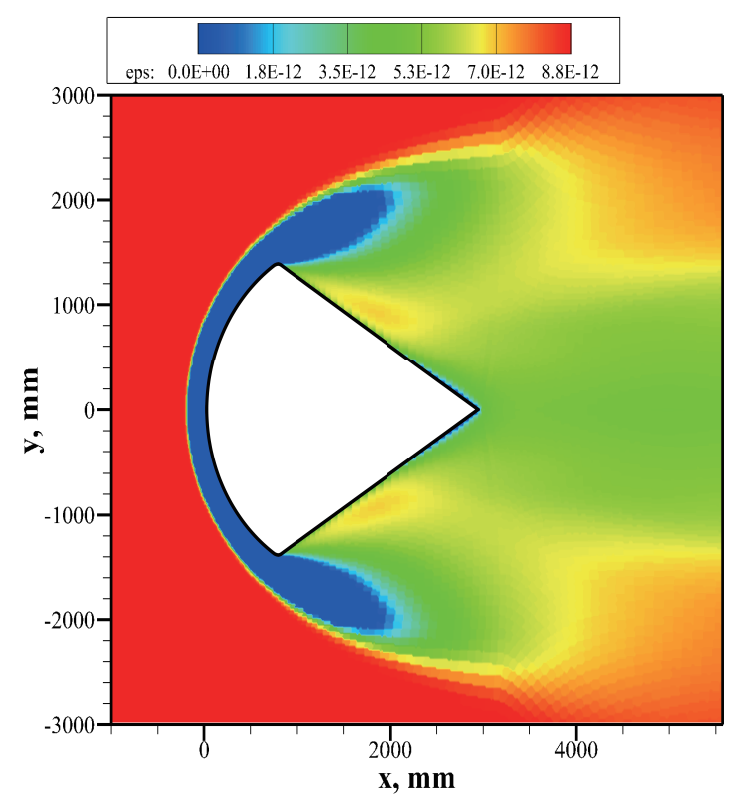

(a) Permittivity $\left(\mathrm{N} / \mathrm{V}^{2}\right)$

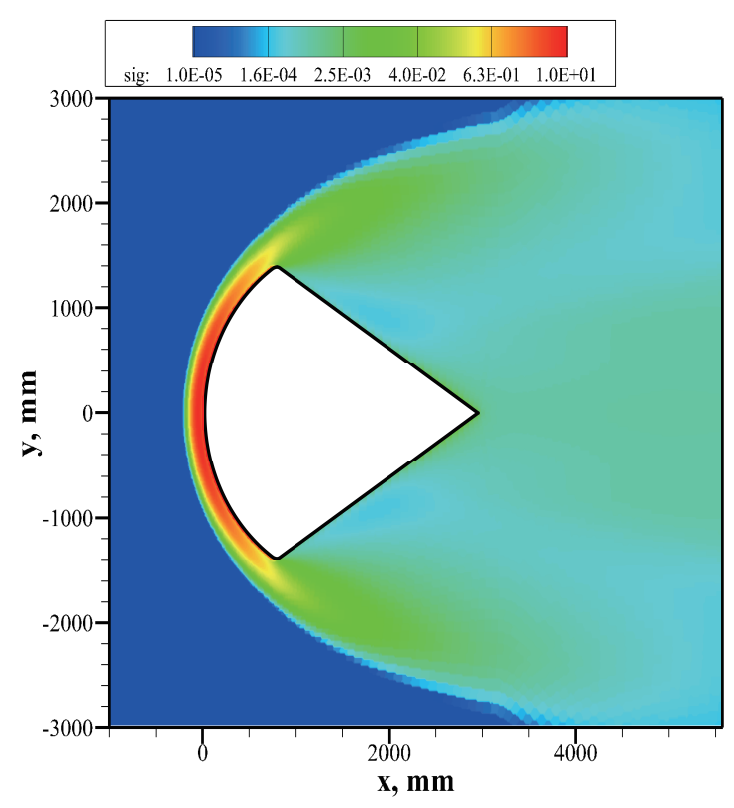

(b) Dielectric conductivity $(\mathrm{S} / \mathrm{m})$

Figure 7: Distributions of permittivity and dielectric conductivity in $x-y$ plane $(z=0 \mathrm{~mm})$ of FD2TD computational domain around ARD at altitude of $85 \mathrm{~km}$.

is generated at each altitude. There are high-density regions of electrons in the shock layer. After the plasma flow passes through above the shoulder, high-temperature gas flows into the wake with supersonic expansion. Through this process, the plasma becomes cool and rarefied. This could contribute to the decrease in the number density of the electrons at the rear and the absence of the RF blackout phenomena during the flight. On the shock layer surface, the electromagnetic waves are perfectly reflected at each altitude, and wave energies are observed to attenuate almost completely in the front region of the ARD. In addition, attenuation by high conductivity near the ARD rear surface is partly confirmed. At the altitudes of $80 \mathrm{~km}$ and $70 \mathrm{~km}$, because highly dense plasma remains or is generated in the wake region, the electromagnetic waves are strongly reflected and attenuated, whereas a limited number of waves escape from the aperture of the plasma. The TDRS is always on the back side of the ARD during flight. At these altitudes, it is thought that the intensity of the radio waves that the TDRS catches becomes weak. At an altitude of $75 \mathrm{~km}$, the electromagnetic waves are perfectly encaged, and the RF blackout occurs. On the other hand, the number density of the electrons decreases, and the electromagnetic waves can propagate sufficiently in the wake region of the ARD at an altitude of less than $60 \mathrm{~km}$.

The dependency investigations of the computational grids used in the CFD and FD2TD simulations are performed using fine meshes with approximately double the number of grids. It is confirmed that the computational grids converge.

\subsection{Attenuation by Plasma Effect}

In the previous sections, the flow-field properties and electromagnetic wave behaviors for a baseline physical model were shown. Chemical reaction models may show an inherent discrepancy with the true value when adopted for a wide temperature range, whereas reactions have large influences on the formation of electrons and ions around the vehicle. Hence, the 


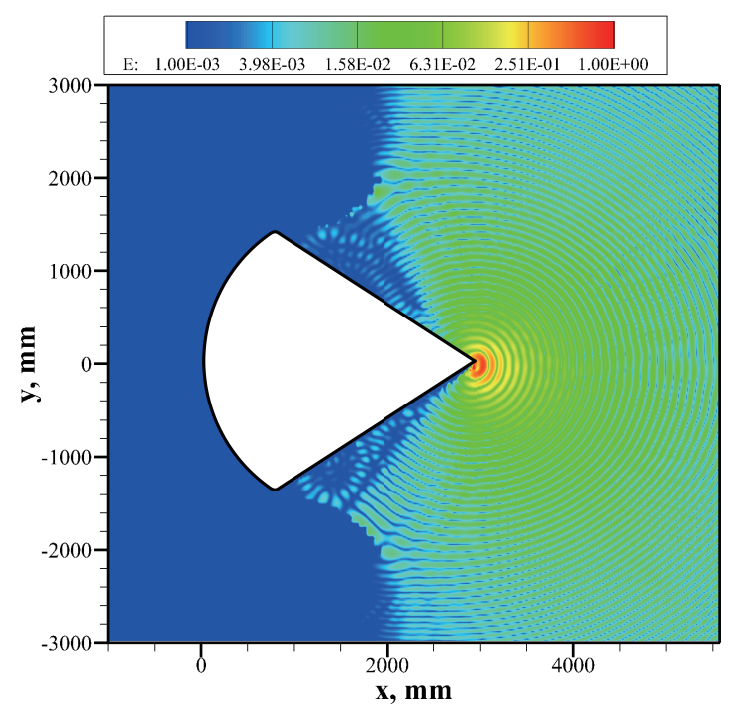

(a) altitude $85 \mathrm{~km}$

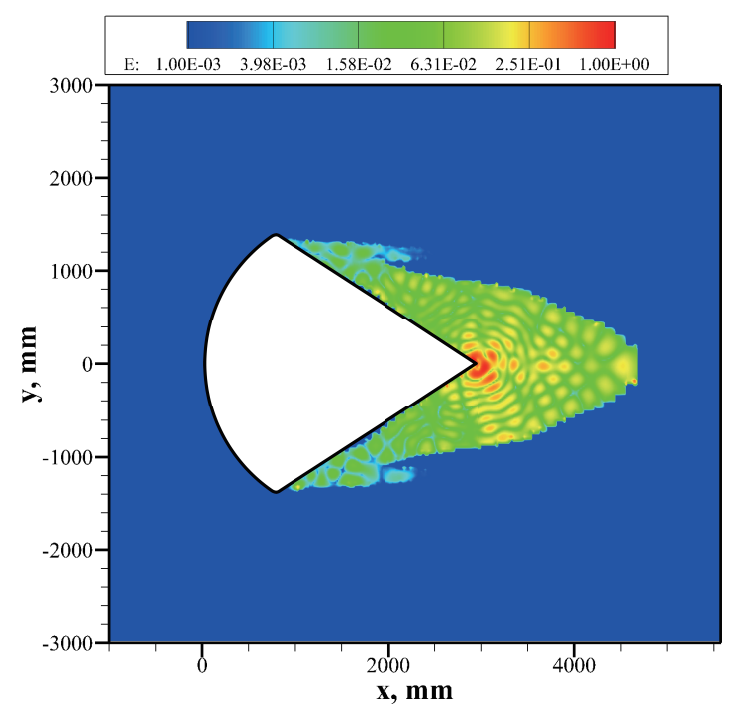

(c) altitude $75 \mathrm{~km}$

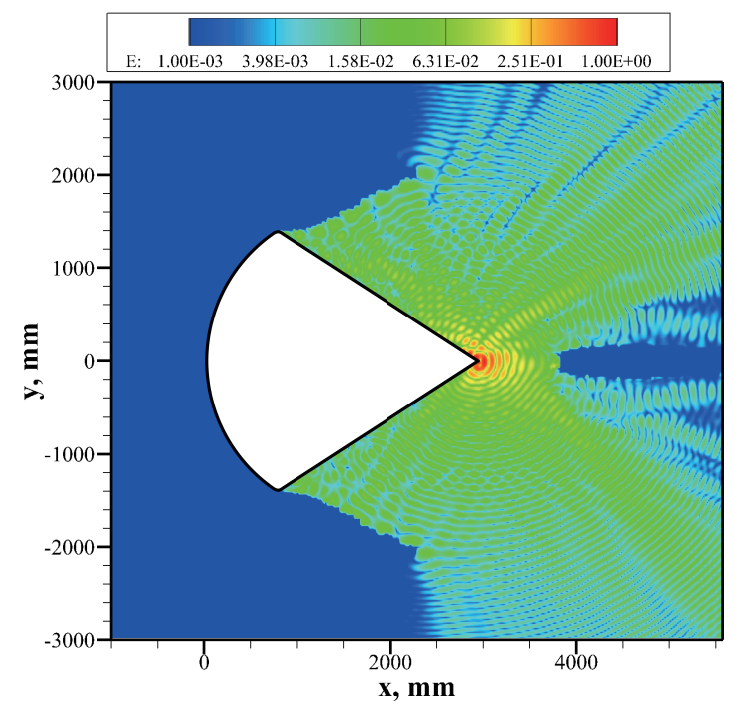

(e) altitude $60 \mathrm{~km}$

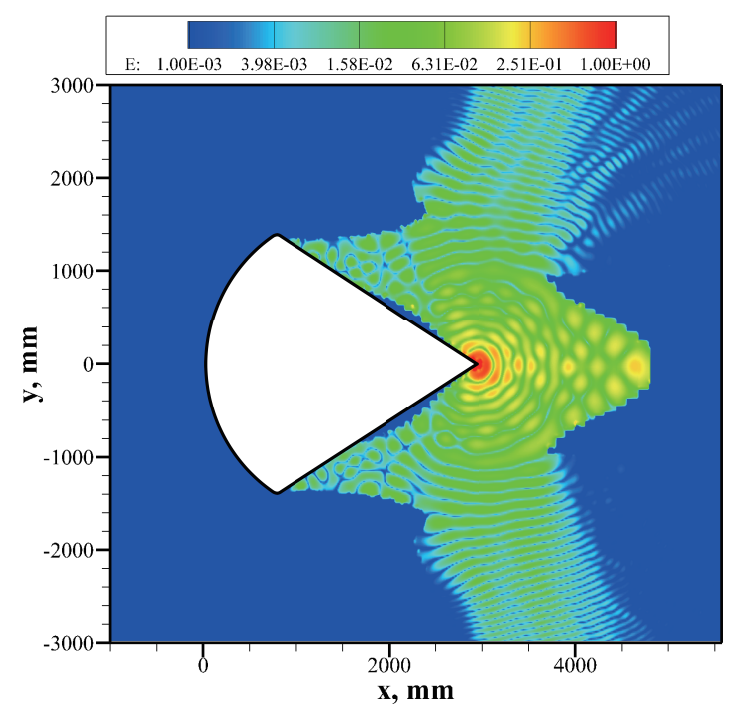

(b) altitude $80 \mathrm{~km}$

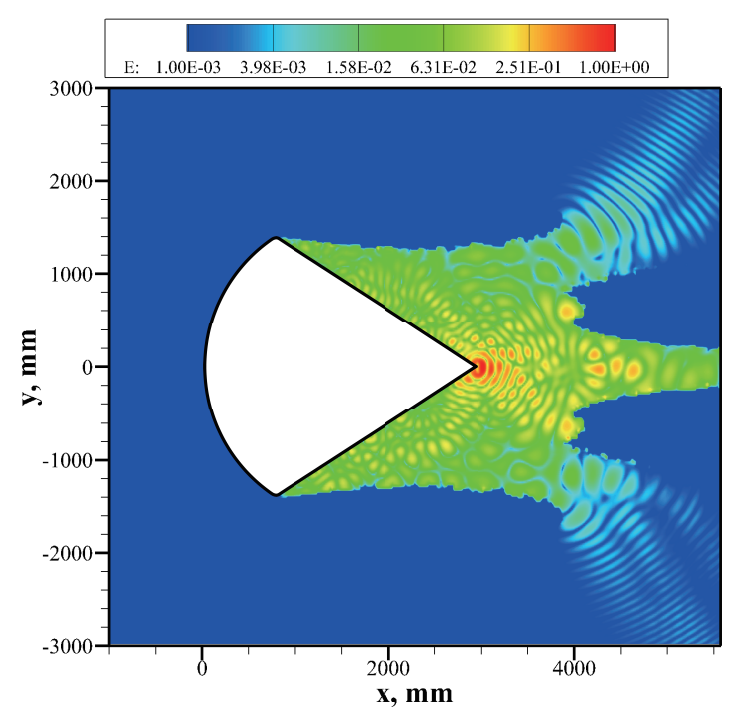

(d) altitude $70 \mathrm{~km}$

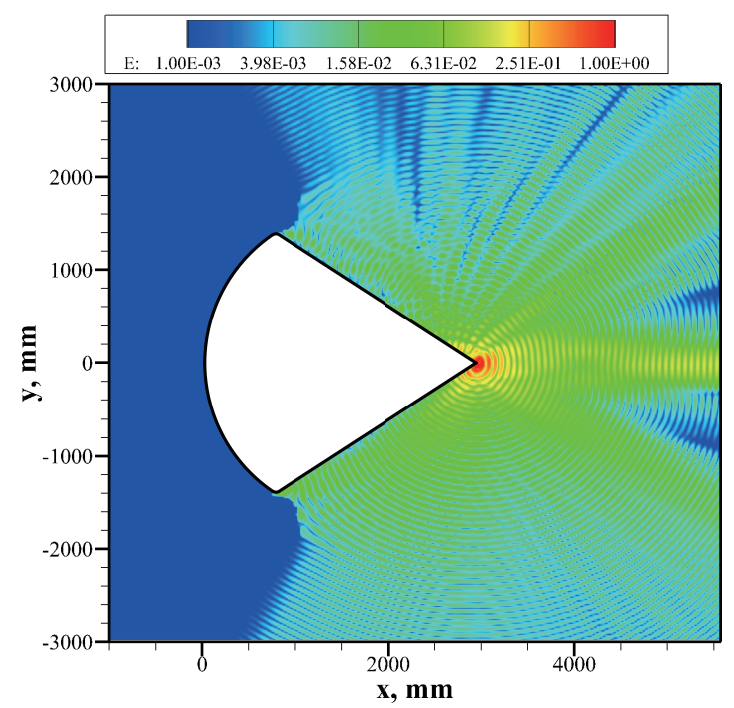

(f) altitude $50 \mathrm{~km}$

Figure 8: Distributions of electric field in $\mathrm{x}-\mathrm{y}$ plane $(\mathrm{z}=0 \mathrm{~mm})$ of FD2TD computational domain around ARD at each altitude. 
Table 2: Forward reaction factors

\begin{tabular}{cccccccccc}
\hline \hline factor & case1 & case2 & case3 & case4 & case5 & case6 & case7 & case8 & case9 \\
\hline$f_{A I 1}$ & 1 & 5 & 1 & 1 & 5 & 0.2 & 1 & 1 & 0.2 \\
$f_{A I 2}$ & 1 & 1 & 5 & 1 & 5 & 1 & 0.2 & 1 & 0.2 \\
$f_{A I 3}$ & 1 & 1 & 1 & 5 & 5 & 1 & 1 & 0.2 & 0.2 \\
\hline \hline
\end{tabular}

numerical results with a given model inevitably have some uncertainty, and this can reduce the reliability of the numerical prediction. In the freestream velocity and density ranges considered here, one of the most significant ionization reactions is the associative reaction, as follows:

$$
\begin{gathered}
\mathrm{N}+\mathrm{N} \rightleftharpoons \mathrm{N}_{2}^{+}+\mathrm{e}^{-}, \\
\mathrm{O}+\mathrm{O} \rightleftharpoons \mathrm{O}_{2}^{+}+\mathrm{e}^{-}, \\
\mathrm{N}+\mathrm{O} \rightleftharpoons \mathrm{NO}^{+}+\mathrm{e}^{-} .
\end{gathered}
$$

It is possible that the reaction rates have error because the rate models are reconstructed based on data measured using a shock tube, and a discrepancy is expected from the baseline physical model. To estimate this discrepancy, we performed flow-field and electromagnetic wave simulations using various model combinations and evaluated the uncertainty of the plasma attenuation by changing the reaction rates of the associative ionizations. In the present study, uncertainty calculations were performed by multiplying the forward reaction rates of the three associative ionizations (AI1, AI2, and AI3) by the factors $f_{\mathrm{AI} 1}, f_{\mathrm{AI} 2}$, and $f_{\mathrm{AI} 3}$, respectively, as

$$
k_{\mathrm{f}, \mathrm{AI} 1}^{*}=f_{\mathrm{AI} 1} k_{\mathrm{f}, \mathrm{AI} 1}, \quad k_{\mathrm{f}, \mathrm{AI} 2}^{*}=f_{\mathrm{AI} 2} k_{\mathrm{f}, \mathrm{AI} 2}, \quad k_{\mathrm{f}, \mathrm{AI} 3}^{*}=f_{\mathrm{AI} 3} k_{\mathrm{f}, \mathrm{AI} 3} .
$$

The condition matrix is summarized in Table 2. Dissociation reactions such as heavy-particle impact dissociation can affect the associative reactions because they generate atoms that are consumed in the associative ionization reactions. It is possible that the uncertainty of these reactions needs to be considered. However, because these are indirect reactions that produce ion species and electrons, the associative reactions are the focus of this study.

In the present simulation, the current densities generated by the presence of electromagnetic waves are first integrated on the far-field boundary faces where the TDRS is projected in view of the ARD. Then, the plasma attenuation is obtained by dividing the integrated current at each altitude by a reference current on the boundary faces when the electromagnetic waves propagate in a space where there is no plasma ("free"). The plasma attenuation $G_{\mathrm{PA}}$ is calculated as follows:

$$
G_{\mathrm{PA}}=20 \log \left(\frac{\sum I_{b d}}{\sum I_{b d, \text { free }}}\right)
$$

To appropriately estimate the intensity of an electromagnetic wave that reaches the TDRS, we consider the effects of the TDRS direction from the viewpoint of the ARD. The range of angles between the TDRS location and the ARD axis was $110^{\circ}-120^{\circ}$ at altitudes ranging from $90 \mathrm{~km}$ to $40 \mathrm{~km}$ (Fig. 2), if the ARD flew with the angle of attack of approximately $-20^{\circ}$. For an electromagnetic wave in this direction, we evaluate the plasma 
attenuation defined by Eq. (10) and compare the results with the measured data ("case A"). This evaluation method is appropriate when calculating the flow field around the ARD considering the angle of attack of $-20^{\circ}$ in the plasma flow simulation. However, because the present CFD model assumes two-dimensional axisymmetry for a lower computational cost and simplicity, there is a difference from the actual flight, whereas an assumption of three-dimensions is adopted in the present FD2TD method. Hence, it is thought that the electromagnetic wave actually propagates across a broader area than the $110^{\circ}-120^{\circ}$ direction. To estimate the effect in a broader field, we further extend the area used to evaluate the plasma attenuation. In the present study, we consider the four faces of the ARD to be lateral in the FD2TD computational domain ("case B").

Comparisons of the plasma attenuation between the experimental and computational results for cases A and B are shown in Figs. 9 and 10, respectively. Note that we refer to Ref. [7] for the measured plasma attenuation in the ARD flight. These show gains for the electromagnetic waves attenuated by the presence of plasma around the vehicle. No large qualitative discrepancies in the plasma attenuation history appear between case A and case B. However, at altitudes from $92 \mathrm{~km}$ to $87 \mathrm{~km}$ for case A, the predicted plasma attenuation becomes greater than 1 . This is because the electromagnetic wave is reflected and diffracted by the plasma. Then, the current density at the far-field boundary faces increases compared to that in the free-space case. If the computational domain is sufficient large, it is thought that this overshoot is mitigated.

The computational results indicate that the dispersions among the reaction rates are large at higher altitudes and small at lower altitudes. This is because of the nonequilibrium of the flow field around the ARD. Similar trends were shown in plasma flow and electromagnetic wave simulations performed with various physical models for an inflatable vehicle [8]. In the rear region, the flow field is close to chemical equilibrium in the case of a large reaction rate (cases 2-5), whereas the flow is close to being chemically frozen in the small-reaction-rate cases (cases 6-9). Because the temperatures rapidly decrease in the rear region, the number density of the electrons rapidly decreases if the flow is in chemical equilibrium.

The computed plasma attenuations for both case A and case B show good agreement with the measured ones at higher altitudes. These results imply that the present combined simulation model of CFD and FD2TD predicts the plasma attenuation well around a reentry vehicle at such altitudes. However, an RF blackout is predicted from $77 \mathrm{~km}$ to $73 \mathrm{~km}$ in the baseline case (case 1) of the simulation, as expected in the prediction of the electron distribution. No RF blackout occurs in the large-reaction-rate cases (cases 2 and 5), although a strong attenuation is confirmed. There appears to be no blackout period in the experiment during reentry flight. These discrepancies may be attributed to the uncertainty of the reaction rate model. Another reason is thought to be the angle of attack in the actual flight. To lower the computational cost, in the present study, the flow field is assumed to be axisymmetric for all the computational conditions. However, the ARD reentered with an angle of attack of approximately $-20^{\circ}$. Because the freestream inflows in a sideways direction toward the ARD axis, it is possible that the distribution of the plasma properties changes compared to the axisymmetric simulation case, even though the fundamental phenomena are not believed to change significantly. A more detailed discussion of this issue is left for future studies. At altitudes lower than $70 \mathrm{~km}$, the computational results overestimate the measured plasma attenuation. That is, the present simulation model underestimates the number density of the electrons in the ARD rear region. Many heat shields generally include impurities such as sodium and potassium. These impurities have low ionization levels and can increase the number density of the electrons in the flow field around vehicles when being heated and 
ablated. Because the plasma attenuation and RF blackout are sensitive to the presence of electrons, impurities can be a significant issue. According to Ref. [7], during the ARD reentry flight, the heat flux on the front shield rapidly increased at an altitude of approximately 75 $\mathrm{km}$ and reached a peak value (approximately $1.2 \mathrm{MW} / \mathrm{m}^{2}$ ) at $64.6 \mathrm{~km}$. The ARD heat shield was an ablator, and it is possible that impurities were outgassed when sufficiently heated. Thus, it is reasonable to say that the plasma attenuation was enhanced at the lower altitudes.
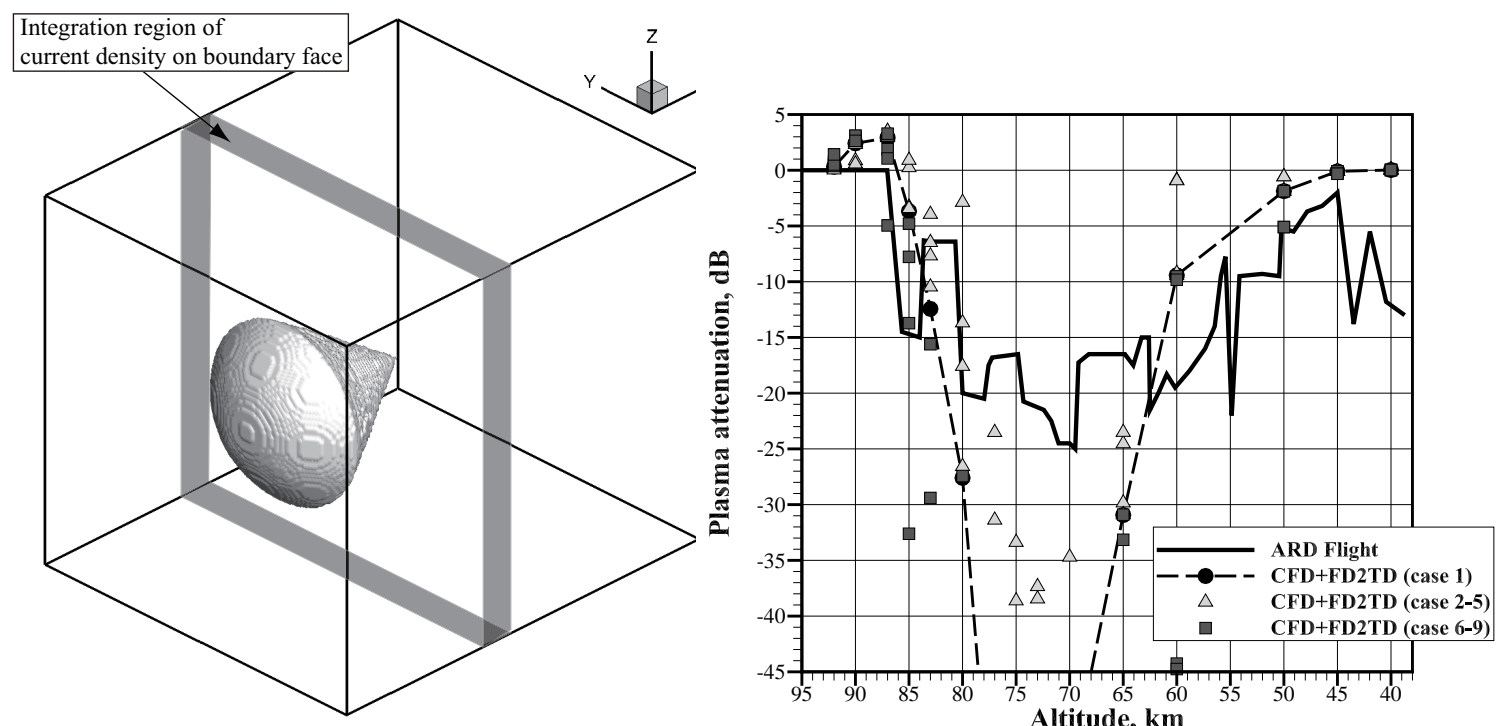

Figure 9: Gain comparison of plasma attenuation (case A; considering angle range of TDRS direction to $\mathrm{ARD}$ axis from $110^{\circ}$ to $120^{\circ}$ ).
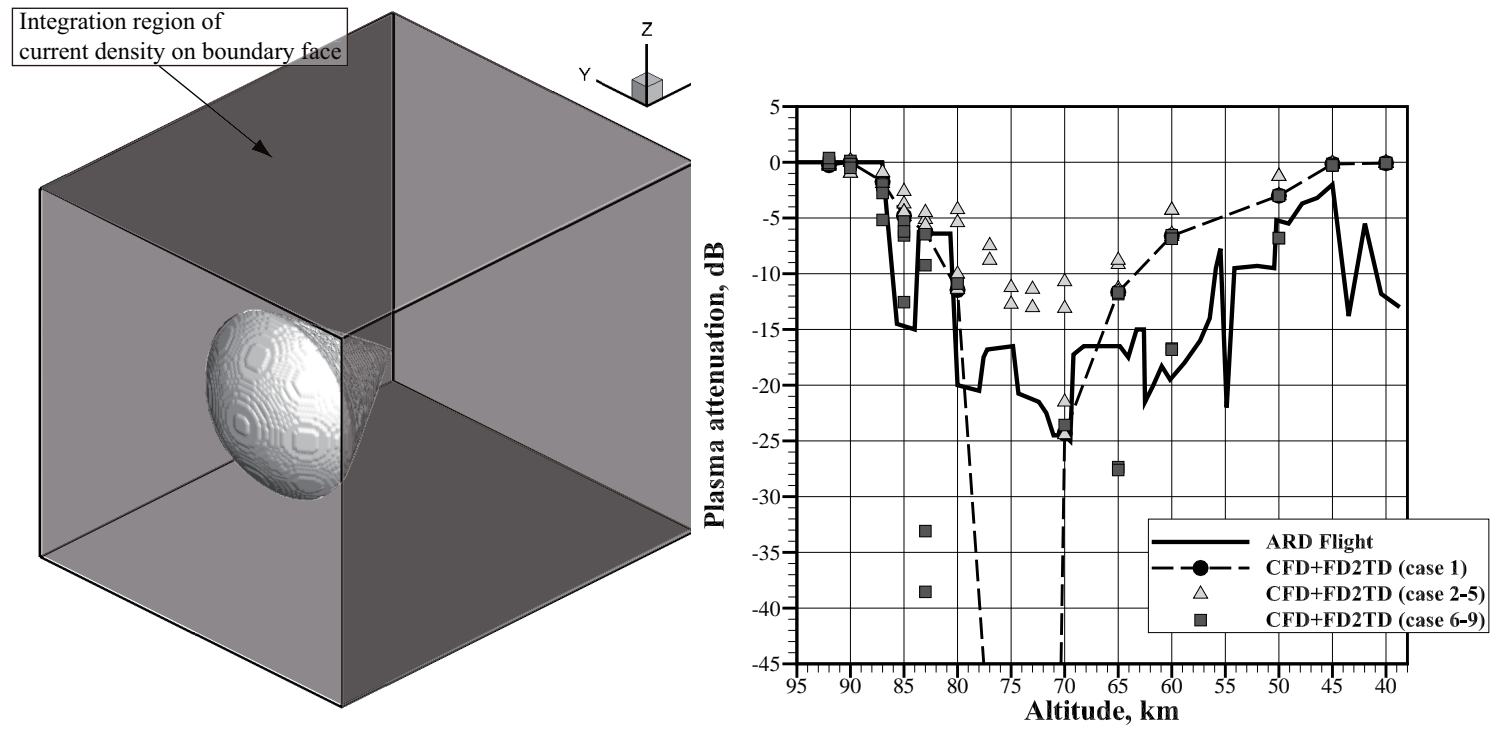

Figure 10: Gain comparison of plasma attenuation (case B; considering four faces of ARD to be lateral in FD2TD computational domain). 


\section{Conclusions}

Numerical simulations of plasma flows and electromagnetic waves around a reentry vehicle were performed to evaluate the radio frequency blackout and plasma attenuation during atmospheric reentry. In this study, a mathematical formulation of the complicated flow fields in the shock layer was established, and its implementation through an effective numerical procedure was achieved. In addition, based on the computational results of the plasma flow simulation, the electromagnetic wave behaviors were investigated in detail using the frequency-dependent finite-difference time-domain method. To validate the combined simulation model, the plasma attenuation was measured in the communication between the atmospheric reentry demonstrator and the tracking and data-relay satellite during the reentry flight. The present computations were performed for 15 cases with altitudes between $92 \mathrm{~km}$ and $40 \mathrm{~km}$ based on the reentry orbit data. Moreover, a parametric analysis with different reaction models for the associative ionizations was performed for a more detailed discussion. A comparison of the measured plasma attenuation and predicted results generally showed good agreement. It was confirmed that the present simulation model can be effectively used to investigate the radio frequency blackout and plasma attenuation of the radio wave communication between a reentry vehicle and a data-relay satellite and for the design and development of reentry vehicles.

On the other hand, it was seen that the combined simulation model has the potential to predict a radio frequency blackout that was not observed at a certain altitude in the actual flight, even though a strong attenuation was measured. In the present study, for ensuring simplicity and lower computational cost, an axisymmetric condition was imposed for the flow field, whereas a three-dimensional model of the flow field may change the formation of the plasma in the wake region of the vehicle. In addition to the three-dimensional effect, the uncertainty of the reaction rate models also has an influence on the prediction of the blackout and plasma attenuation. The possible contributions of these issues may need to be examined to develop the calculation further in a future study.

\section{Acknowledgments}

The computation was mainly carried out using the computer facilities at the Research Institute for Information Technology, Kyushu University.

\section{References}

[1] Takahashi, Y., Yamada, K., and Abe, T., "Radio Frequency Blackout Possibility for an Inflatable Reentry Vehicle," AIAA Paper 2012-3110.

[2] Takahashi, Y., Yamada, K., and Abe, T., "Examination of Radio Frequency Blackout for an Inflatable Vehicle during Atmospheric Reentry," Journal of Spacecraft and Rockets. (in press).

[3] Kim, M., Keidar, M., and Boyd, I. D., "Analysis of an Electromagnetic Mitigation Scheme for Reetnry Telemetry Through Plasma," Journal of Spacecraft and Rockets, Vol. 45, No. 6, 2008, pp. 1223-1229. 
[4] Kunz, K. S. and Luebbers, R. J., The Finite Difference Time Domain Method for Electromagnetics, CRC Press, Boca Raton, 1993.

[5] Kinefuchi, K., Funaki, I., and Abe, T., "Frequency-Dependent FDTD Simulation of the Interaction of Microwaves With Rocket-Plume," IEEE Transactions on Antennas and Propagation, Vol. 58, No. 10, 2010, pp. 3282-3288.

[6] Cummer, S. A., "An Analysis of New and Existing FDTD Methods for Isotropic Cold Plasma and a Method for Improving Their Accuracy," IEEE Transactions on Antennas and Propagation, Vol. 45, No. 3, 1997, pp. 392-400.

[7] Tran, P., Paulat, J. C., and Boukhobza, P., "Re-entry Flight Experiments Lessons Learned - The Atmospheric Reentry Demonstrator ARD," Education Notes RTO-ENAVT-130 - Flight Experiments for Hypersonic Vehicle Development, Vol. 10, 2007, pp. $10-1-10-46$.

[8] Takahashi, Y., Kihara, H., and Abe, K., "Improvement of Potential Drop Predictions for Plasma Wind Tunnels by Cathode Sheath," Journal of Thermophysics and Heat Transfer, Vol. 26, No. 3, 2012, pp. 540-544.

[9] Gupta, R. N., Yos, J. M., Thompson, R. A., and Lee, K.-P., "A Review of Reaction Rates and Thermodynamic and Transport Properties for an 11-Species Air Model for Chemical and Thermal Nonequilibrium Calculations to $30000 \mathrm{~K}$," NASA RP-1232.

[10] Fertig, M., Dohr, A., and Frühaufu, H.-H., "Transport Coefficients for High-Temperature Nonequilibrium Air Flows," AIAA Paper 98-293\%.

[11] Fertig, M., Dohr, A., and Frühauf, H.-H., "Transport Coefficients for High-Temperature Nonequilibrium Air Flows," Journal of Thermophysics and Heat Transfer, Vol. 15, No. 2, 2001, pp. 148-156.

[12] Jones, W. W. and Boris, J. P., "An Algorithm for Multispecies Diffusion Fluxes," Computer and Chemistry, Vol. 5, No. 2-3, 1981, pp. 139-146.

[13] Curtiss, C. F. and Hirschfelder, J. O., "Transport Properties of Multicomponent Gas Mixture," Journal of Chemical Physics, Vol. 17, No. 6, 1949, pp. 550-555.

[14] Park, C., "Review of Chemical-Kinetic Problems of Future NASA Missions, I: Earth Entries," Journal of Thermophysics and Heat Transfer, Vol. 7, No. 3, 1993, pp. 385-398.

[15] Park, C., Nonequilibrium Hypersonic Aerothermodynamics, Wiley, New York, 1990.

[16] Park, C., "Rotational Relaxation of $\mathrm{N}_{2}$ Behind a Strong Shock Wave," Journal of Thermophysics and Heat Transfer, Vol. 18, No. 4, 2004, pp. 527-533.

[17] Millikan, R. C. and White, D. R., "Systematics of Vibrational Relaxation," The Journal of Chemical Physics, Vol. 39, No. 12, 1963, pp. 3209-3213.

[18] Park, C., "Problems of Rate Chemistry in the Flight Regimes of Aeroassisted Orbital Transfer Vehicles," AIAA Paper 84-1730.

[19] Appleton, J. P. and Bray, K. N. C., "The Conservation Equations for a Nonequilibrium Plasma," Journal of Fluid Mechanics, Vol. 20, No. 4, 1964, pp. 659-672. 
[20] Mitchner, M. and Jr., C. H. K., Partially Ionized Gases, Wiley, New York, 1973.

[21] Lee, J.-H. and White, D. R., "Thermal Design of Aeroassisted Orbital Transfer Vehicles," in Nelson, H. F., ed., "Basic Governing Equations for the Flight Regimes of Aeroassisted Orbital Transfer Vehicles (Progress in Astronautics and Aeronautics)," AIAA, New York, Vol. 96, pp. 3-53, 1985.

[22] Nishida, M. and Matsumoto, M., "Thermochemical Nonequilibrium in Rapidly Expanding Flows of High-Temperature Air," Zeitschrift für Naturforcuhung, Teil A: Physik, Physikalische Chemie, Kosmophysik, Vol. 52, No. 4, 1997, pp. 358-368.

[23] Lazdinis, S. S. and Petrie, S. L., "Free Electron and Vibrational Temperature Nonequilibrium in High Temperature Nitrogen," Physics of Fluids, Vol. 17, No. 8, 1974, pp. 1539-1546.

[24] Lee, J.-H., "Electron-Impact Vibrational Relaxation in High-Temperature Nitrogen," Journal of Thermophysics and Heat Transfer, Vol. 7, No. 3, 1993, pp. 399-405.

[25] Gnoffo, P. A., Gupta, R. N., and Shinn, J. L., "Conservation Equations and Physical Models for Hypersonic Air Flows in Thermal and Chemical Nonequilibrium," NASA TP-286\%.

[26] Shima, E. and Kitamura, K., "Parameter-Free Simple Low-Dissipation AUSM-Family Scheme for All Speeds," AIAA Journal, Vol. 49, No. 8, 2011, pp. 1693-1709.

[27] Bussing, T. R. A. and Murman, E. M., "Finite-Volume Method for the Calculation of Compressible Chemically Reacting Flows," AIAA Journal, Vol. 26, No. 9, 1988, pp. 1070-1078.

[28] Mur, G., "Absorbing Boundary Conditions for the Finite-Difference Approximation of the Time-Domain Electromagnetic-Field Equations," IEEE Transactions on Electromagnetic Compatibility, Vol. EMC-23, No. 4, 1981, pp. 377-382. 